\title{
Analysis of the Combination between the Architecture Structure and Formal Beauty
}

\author{
Jiang Fang ${ }^{1} \mathrm{Li}$ Jiao ${ }^{2}$ \\ ${ }^{1}$ Hubei University of Education, Wuhan, China \\ ${ }^{2}$ Wuhan University of Technology Huaxia College, Wuhan, China
}

\begin{abstract}
In the past, building structure is only to keep the stability and ensure the function of the building. With continuously high technology and new materials applied in the area of building now, structure has been the new and important factor of architecture spacial form. The combination of architecture morphology and structuralism is the combination of thought and practice. It constantly pushes forward the thought and method of architecture design. This thesis aims to explore how to achieve some methods of uniting the structure and architecture forms, to emphasize that architects pay much attention to architecture structure so as to achieve aims of new artistic effects in structure design.
\end{abstract}

Keywords: structure design; building structure; architecture form; architectural mechanical; earthquake resistance1.

\section{Introduction}

Through the ages, any outstanding architectural works must also have excellent chic appearance, solid and reasonable structure and contemporary design. Structure of architecture refers to the spatial stress framework of buildings, which can be either completely hidden in the architectural modeling or a part of the architecture itself for its artistic beauty. It is the vessel of human activity and the only way to model the space and form of architecture. For example, the ternary structure (roof, body and pedestal) of Chinese traditional architecture, the traditional column structure of ancient Greek architecture, the vault roof of ancient Rome and the unique structures of Byzantine architecture and Gothic architecture whose architectural mode lings are just shaped by their unique structures. In the long history of world architecture, every transformation of the architectural style is necessarily related to the change of structure system. Or, to put it in another way, the formal beauty and the structure system of architecture have been all the time with the mutual promotion and development.

\section{Relationship between Architectural Structure and} Form

Structure exists in all things on earth, as is observed in a leaf of a plant, a bone of an animal and even virtual network. Meanwhile the structure and the form coexist in all things, and they are closely related to each other. The architectural structure has a predominant influence on its inner space and external styling. Without structure, there wouldn't be any architectural form. Therefore the structure design is the linchpin in the whole architectural designing, which plays a vital role in the appearance effect and structural stability of the entire architecture.

Since the first shabby shelter created by the Chinese ancient appeared, this timber architecture system that supports the roof has constantly been explored and excavated. House constructed in trees in the ancient times is actually the original prototype of timber architecture. Later on, for lack of skills to build roof and for the purpose of a magnificent architecture with military defense in need, ancient people used the compound of rough sand, red mud and lime mixed in certain proportion, together with the ramming craft, to construct tall defensive walls and palaces. To prevent the wooden eaves from rotting by rain, ancient people invented the bucket arch, which extended the eaves as well as enriched the architectural layering. And hip roof, gable and hip roof, pyramidal roof, flush gable roof, 
overhanging gable roof were invented afterwards to increase the differences in classes.

In Western ancient times, much architecture was built for gods, and stone could guarantee the architecture to be taller and stand longer. That's why the Egyptian pyramids, the ancient Greek temples, the ancient Roman Coliseum and medieval cathedrals are all made of stone. But long-span structure space could not be created at that time due to the limited technology, thus the inner structure of the temples normally presented a stone pillar forest effect. In order to get close to gods, the height and design of the pillar became the linchpin of the entire architectural designing, and hence the classical pillar type took form in ancient Greek. To deal with the drainage, the roofs were designed as slope crest, with decoration of some patterns and sculptures, further generating the pediment in the front. The innovation of arch constructing technology and the concrete material developed the architectural function and structure, and gradually arch, pointed arch and flying buttress came into being, making it possible for the long-span structure. With the development of various kinds of decorating techniques, sculpturing, and permutation \& combination of inner space, different styles of architectural form turned up, like Gothic, Baroque, Rococo and Renaissance-style. Since the application of new constructing methods of glass and iron structure, the West ushered the architectural modernization.

Therefore, the several-thousand-year development of structure technique has promoted the development of architectural form throughout Chinese and foreign architectural history.

\section{The Unity of Structure and Shape in Architecture Design}

\subsection{Architectural Structure and Mechanical Aesthetic}

Architectural structure is not only a building's skeletal or back bone, but also is assigned with the task of resisting various natural factors (gravity, load of use, earthquake, wind and snow loads, etc.) What comes first in architectural design is to ensure the unity of structure and shape of a building, with the premise of ensuring the load-bearing and stability.
Under a normal load and a certain force, the whole effect of each single force on the building is zero, so is the overall effect of torque, i.e. the building is in a relatively static equilibrium. Milwaukee Art Museum, the architectural works of the famous Spanish "innovative architect" Santiago Calatrava, is another successful case for innovation on the unity of structure and shape. It is also at the top of the Annual Design standings of the U.S Time in 2001. Architects hold that the mechanical design can express the beauty of a building's shape. This building, by means of mechanical transmission device, opens the wings-alike steel structure on its top, just as seabirds do under the sun. Thus, it is a building with much vitality. Its appropriate structure and free flowing curves enable itself to solve the engineering problems as well as mould its shape features.

Frank Owen Gehry, the famous contemporary American structuralism architect, is renowned for his unique designs with innovative irregular curves and sculpture-alike exterior. His architectural works have an invigorating effect, standing for abstraction and surrealism. His Guggenheim Museum Bilbao is world-known for its weird structure, unique styling and brand-new materials. It is referred to as "The world's most meaningful and beautiful museum".

Gehry often applies open architectural structures and fractural geometry in his works in order to break the tradition and make people feel it as a coincidental change, rather than deliberate. From the traditional aesthetic point of view, most of Gehry's architectural works display absurdness and incredibility to people. No matter how bizarre and illogical his works are, they are still able to give people a sense of stability and reliability on the whole, mainly because his works have a reasonable structural system.

In addition, the building structure directly determines the shape of the building, while the shape of the building has a significant effect on its seismic performance. Unconventional architectural shape may cause potential hazards for buildings. For example, The West Berlin Chamber of former Federal Republic of Germany is a good case in point. Its saddle-shaped roof made of large cantilevered cable net was overturned by a stormy wind in 1980. Terminal $2 \mathrm{E}$ of Charles De Gaulle Airport collapsed soon after the airport was put 
into use. Therefore, taking into account the static balance system of buildings is a prerequisite for ensuring building safety.

Locating between pacific seismic zone and Euro-Asia seismic zone, our country is one of the countries which suffers from the frequent earthquakes and endure the heavy disasters as a result of convergence of Pacific plate and Indian plate. The seismic disaster data shows that, generally, the less complex buildings suffer from relatively light damage since it is easier to analyze the distribution of the actual internal structure force when they are built. So as architects, when we design the structure and shape of the buildings, we must do as following rules:

The surface structure design should be as concise as possible, making it easier to form the stress concentration or deformation concentration, thus forming the seismic weak link. So, more attention should be put on it.

If the vertical structure system is uneven along the vertical stiffness, some part of buildings may initially deform under an earthquake, so make sure that it is uniform and continuous in structure design.

Structures will exist eccentricity for the inconsistency between the center of mass and stiffness, and, as for the building itself, that would give torsion effect as a result of accelerating destruction. So it is very important to keep the consistency between the center of mass and stiffness. What is the most important thing to architectural design is to keep the stable system and load bearing system going well first, and then need to keep the consistency between the structure and shape.

\subsection{Combination of Architectural Structure and Formal Beauty}

\subsubsection{People-oriented}

Architectural form can be seen as a bridge through which the architect and the user can communicate with each other. An architect should consider more about the users' lifestyle, environment, and the users' emotion, demand and other aspects, not just the shallow imitation and the pursuit of the local culture, an architect is like a director who needs his own rational thinking and emotional creating to make a perfect combination of architectural structure and form, allowing users to experience the beauty of architectural space and architectural art.

The China Pavilion in 2010 Shanghai Expo, designed jointly by South China University of Technology and Tsinghua University, was known as the "Oriental Crown", which has applied the traditional elements of Chinese wooden architecture--brackets, the whole China Pavilion was constructed with the traditional structure of "tenon interspersed with layers of overhangs", which gathered together the fine structure and traditional aesthetics so that people can feel the strong vitality of Chinese architecture.

\subsubsection{Faithful to Structure}

Helou Xuan(pavilion), located in the bamboo forest of Shanghai Tayuan Park, was designed by the famous architect Mr. Feng Jizhong. It was awarded bronze prize in 1999 on the 50th anniversary of classic architect of Shanghai. The architectural form was inspired by the folk houses in Zhejiang Province. With four declining roofs, curved ridge, bamboo beams, brick floor, bamboo chair rattan articles, and water surrounding, the architect mingles perfectly with the surrounding bamboos and turns out some special flavor. Here the designer uses the most simple way taking the form as the structure feature and continuing historical culture of the regional architecture, which has showed that the first point of structural design is to use the real structure to mould true form, and start from the moment to design honestly and be faithful to the design.

\subsubsection{Earthy Ideas Make Amazing Creation}

Modern architect Mies van DE lo (Ludwig Mies van der Rohe) of the Farnsworth house is known as the "house with view", which is all made by steel and glass, with 8 steel columns like "I" shape supporting the ground and the top, all sides are full-length glasses. Apart from the closed space which hides a small bathroom and mechanical equipments, there is no other fixed segmental space. This building has extreme simplicity of nature and is full of controversy, and of the most romantic characteristics.

\subsubsection{Bionic Structure Design}

Now more and more architects prefer to design construction from the perspective of bionics similar to some natural biological structure. For example, known 
as "the fourth generation of stadium" of the Chinese national stadium "bird's nest" design inspires from nature bird nest, the structures are exposed, woven by the giant shape of saddle steel truss. Associated with the "bird's nest" is national swimming center "water cube", whose design simulates the arrangement of water molecules and the natural structure of soap bubbles. the membrane structure is at the top in the world. This peculiar and creative configuration has never appeared in the building structure. These bionic architectures not only make things in the nature more closer to people's life, but also show the harmony between human and nature in the deep structure, thus enable people to experience the power of "the harmony of heaven and men".

\subsubsection{Unconventional Design}

Renowned engineer and architect Pier Luigi Nervi said in his Art and Science of Building : "Architecture is, and must be a synthesis of technology and art, rather than a simple combination of technique and art." From Frank Owen Gehry to Peter Eisenman, Daniel libeskind and Renzo Piano, etc., these master architects' works are full of various artistic effects, such as instability, distortion, growth, thrilling and novelty. These effects bring a strong visual impact, not only meet the needs of the diversification of consumer choice, but also stimulate the users' further interpretation and exploration of the building. Although they do not keep to the beaten track, however, in the process of thinking, they will take both building structure and form design into consideration, respect the rule of structural mechanics and form rule. Their works are like bones and skins which are inseparable as an unity of structure and form.

\subsubsection{Ecological and Sustainable Design}

Nowadays, in the emerging global energy crisis, the architectural design of sustainability in the very great degree has become one of the most important factors that affects mankind's living environment in the future. Therefore, architects and structure engineers should take natural lighting and ventilation into accounts at the beginning of designing architectural structure and form, control energy consumption of outside building, choose recycled construction materials, reduce the waste of non-renewable resources, thus creating a sustainable development of human building environment.

\section{Conclusion}

The generation of architectural form can derive from the architects' mind, can come from the experience of engineers $\&$ architects and can also come from the nature and even can come from the unconscious mind. One of the important purposes of architects engaging in the architectural design and creation is to pursuit the beauty of the architecture form. In order to realize the perfect combination of the architectural art and the architectural technology, the unity of the structure and form of the architecture should not only reflect in external form, but also reflect on the combination of the internal laws. The innovation of the building structure system provides reliable evidences for architects' unconventional modeling design. Meanwhile the development of the architectural modeling makes the structure system on the way of its update dare not neglect.

$\star$ Funded by the Excellent Research Teachers Team Construction Projects of Hubei University of Education (2012K303)

\section{References}

[1] kang Qi. Architecture·Space·Form [J]. Journal of Southeast University, 2000(1)

[2][German] written by Curt Siegel, Translated by Cheng Yingxi, checked by Feng Jizhong [M]. Structure and Form in Modern Architecture. China Architecture \& Building Press, 1981

[3] Xi Liu. The Recognition of the Architectural Configuration from the Structural Perspective[D]. Master Degree Paper, 2009

[4] Keqi Wang. Discussion on the Structure Form's Architectural Representation [J]. Journal of Jilin Architectural \& Civil Engineering, 2010(6) 